\title{
Fournier's gangrene: Clinical case and review of the literature
}

\author{
Remigio Pernetti ${ }^{1}$, Fabiano Palmieri ${ }^{1}$, Elisabetta Sagrini ${ }^{2}$, Marco Negri ${ }^{3}$, Claudio Morisi ${ }^{4}$, \\ Andrea Carbone ${ }^{5}$, Paolo Bassi ${ }^{6}$, Salvatore Voce ${ }^{1}$ \\ ${ }^{1}$ UO Urology, Santa Maria delle Croci Hospital, Ravenna, Italy; \\ ${ }^{2}$ UO Internal Medecine, Santa Maria delle Croci Hospital, Ravenna, Italy; \\ ${ }^{3}$ UO General Surgery, Santa Maria delle Croci Hospital, Ravenna, Italy; \\ ${ }^{4}$ Ambulatory Surgery Wounds-Necrotic Ulcers, Santa Maria delle Croci Hospital, Ravenna, Italy; \\ ${ }^{5}$ UO Plastic Surgery, Santa Maria delle Croci Hospital, Ravenna, Italy; \\ ${ }^{6}$ UO Infectious Diseases, Santa Maria delle Croci Hospital, Ravenna, Italy.
}

\begin{abstract}
Summary
Fournier's gangrene is a life-threatening acute necrotizing fasciitis of perianal,genitourinary and perineal areas. Nowadays, is well known that Fournier gangrene is almost never an idiopathic disease. In this article we report a case of a 70-year-old patient that initially was not treated properly. The gold standard therapy of the Fournier's gangrene remains today a complete, early and extended surgical debridement.
\end{abstract}

KEY WORDS: Fournier's gangrene; Necrotizing fasciitis; Scrotal gangrene; Perianal abscess; Surgical debridement; Staphylococcus aureus, Klebsiella pneumonia; Pseudomonas aeruginosa; Proteus mirabilis; Eenterococci; Bacteroides fragilis.

Submitted 22 January 2016; Accepted 22 May 2016

\section{INTRODUCTION}

Fournier's gangrene is a life-threatening acute necrotizing fasciitis of perianal, genitourinary and perineal areas (1-4). We describe the case of a diabetic patient with Fournier's disease presented with severe sepsis and successfully treated with urgent deep debridement and reconstructive surgery.

\section{Case report}

A 70-year-old presented to the emergency department of his city with a history of inflamed scrotum and perianal abscess. The medical history was remarkable for diabetes and prostate cancer. He was afebrile and the vital signs were stable. On clinical examination, his scrotum was oedematous and erythematous with well-delineated black necrotic areas. The lactate was within normal limits. The patient was given broad-spectrum antibiotics and IV fluids and urgently referred to Urology department. He was taken to the theatre for a simple incision of the scrotum and of the perianal abscess and debridement by the Urology consultant. He was then transferred to the Emergency Department (ED) of our hospital to perform hyperbaric therapy at the specialized Centre of Ravenna. When he arrived the scrotal skin was all clear- ly gangrenous; gangrenous process spread to the right and left groins and perineum (Figure 1), patient was febrile and complained severe perineal pain. Blood pressure was $87 / 50 \mathrm{mmHg}$, heart rate was 124 beats/min, and respiratory rate was 24 breaths/min with an oxygen saturation of $100 \%$ on room air. Aggressive intravenous (IV) fluid resuscitation with normal saline was begun and, with a provisional clinical diagnosis of Fournier's gangrene, IV clindamycin, and ampicillin/sulbactam, was administered, and urgent surgical consultation was performed. His initial ED labs were remarkable for a white blood cell count of $12,000 / \mathrm{mm}$ and a lactate of 2.2 $\mathrm{mEq} / \mathrm{L}$.

After initial clinical stabilization patient was immediately referred to the surgical theatre. An extensive debridement was carried out with denudation of both testes, proximal penile shaft, and the external aponeurosis in the entire right and left inguinal area extending posteriorly to the perianal area were exposed (Figure 2). The testicles were tied together to prevent the twist but both testicles (Figure 3) were then removed due to the extensive spread of the disease (Figure 4).

The patient became afebrile in two days. After 7 days we started again the patient on hyperbaric oxygen.

Consecutive local treatment consisted of wound irrigation with hydrogen peroxide through multiple catheters with bulky dressings and honey resulting in a clean wound within seven days and healthy granulation within three weeks (Figure 5). A split-level thickness graft was taken from the thigh and used to cover the scrotum and perineum (Figure 6). The patient was discharged at the end of the third week (Figure 7).

\section{Conclusion}

The gold standard terapy of the Fournier's gangrene remains today a complete, early and extended surgical debridement.

Introduction complete, Discussion and Supplementary References are posted on www.aiua.it 


\section{REFERENCES}

1. Eke N. Fournier gangrene: a review of 1726 cases. Br J Surg. 2000; 87:718-728.

2. Paty $R$, Smith AD. Gangrene and Fournier gangrene. Urol Clin North Am. 1992; 19:149-162.

3. Yanar H, Taviloglu K, Ertekin C, et al. Fournier gangrene: risk factors and strategies for management. World J Surg. 2006; 30:1750-1754.

4. Norton KS, Johnson LW, Perry T, et al. Management of Fournier gangrene: an eleven year retrospective analysis of early recognition, diagnosis, and treatment. Am Surg. 2002; 68:709-13.

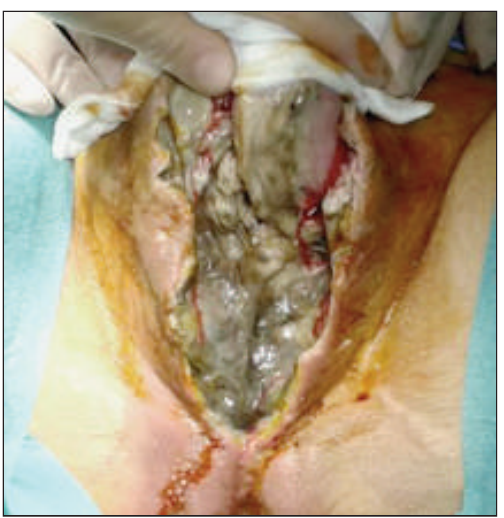

Figure 1.

Gangrenous process spread to the right and left groins and perineum.

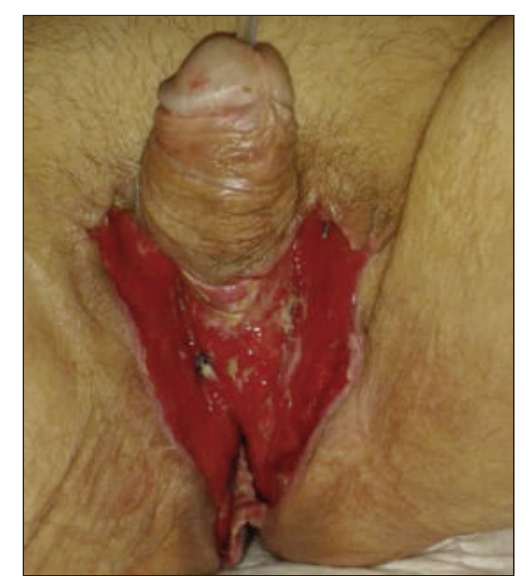

Figure 4.

Both testicles removed due to the extensive spread of the disease.

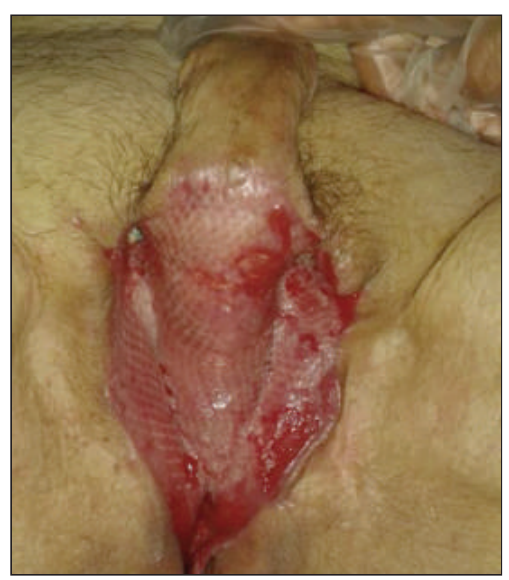

Figure 7.

End of the third week.

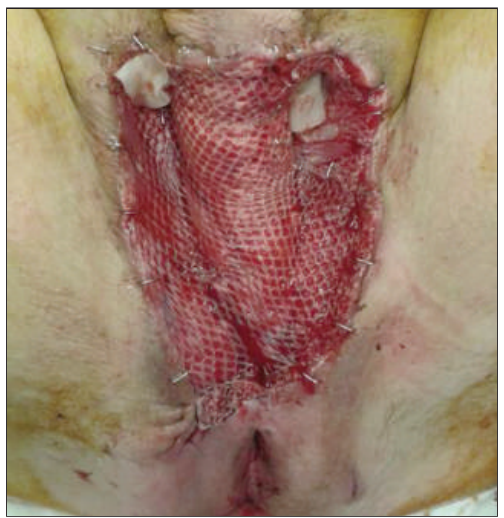

Figure 2.

Extensive debridement.

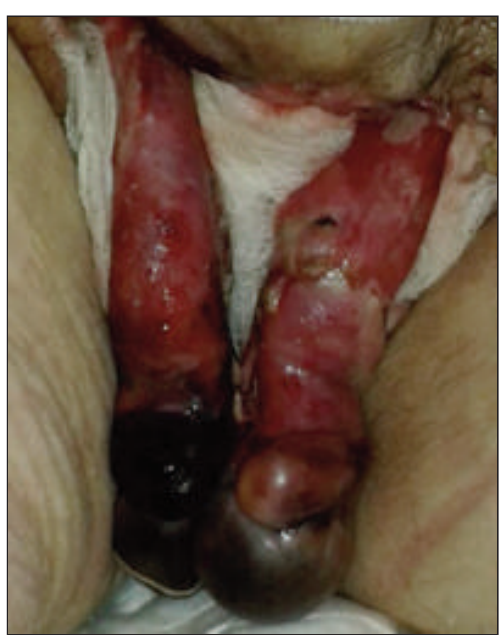

Figure 5.

Healthy granulation within three weeks.

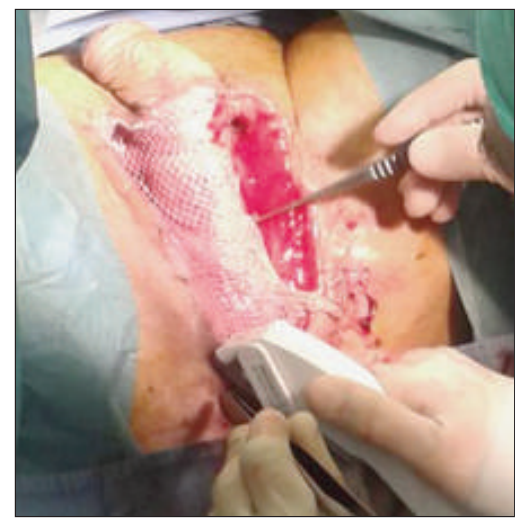

Figure 3.

Testicles were tied together to prevent twisting.

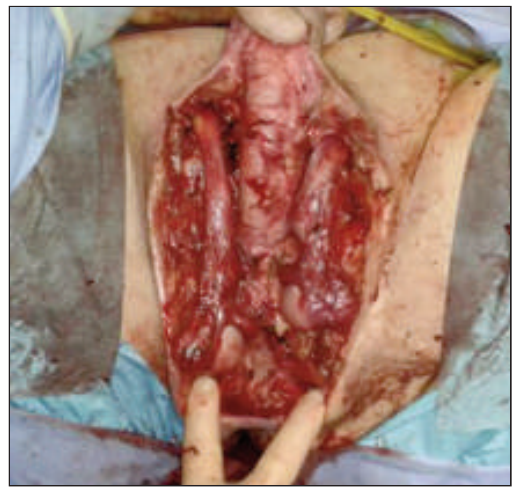

Figure 6.

Split-level thickness graft was taken from the thigh and used to cover the scrotum and perineum.

\footnotetext{
Correspondence

Remigio Pernetti, MD - r.pernetti@virgilio.it

Fabiano Palmieri, MD - Salvatore Voce, MD, Prof

UO Urology, Santa Maria delle Croci Hospital, Ravenna, Italy

Elisabetta Sagrini, $M D$

UO Internal Medecine, Santa Maria delle Croci Hospital, Ravenna, Italy

Marco Negri, MD

UO General Surgery, Santa Maria delle Croci Hospital, Ravenna, Italy

Claudio Morisi, MD

Ambulatory surgery wounds-necrotic ulcers, Santa Maria delle Croci Hospital, Ravenna, Italy

Andrea Carbone, MD

UO Plastic Surgery, Santa Maria delle Croci Hospital, Ravenna, Italy

Paolo Bassi, MD

UO Infectious Diseases, Santa Maria delle Croci Hospital, Ravenna, Italy
} 